\title{
Potential Distribution of the Alien Invasive Brown Tree Snake, Boiga irregularis (Reptilia: Colubridae) ${ }^{1}$
}

\author{
Dennis Rödder ${ }^{2,3,4}$ and Stefan Lötters ${ }^{3}$
}

\begin{abstract}
The Brown Tree Snake (Boiga irregularis) is native to Southeast Asia and Australia and has been introduced to Guam. There it causes major ecological and socioeconomic problems and is considered to belong to the 100 worst alien invasive species worldwide. We used a maximum entropy-based Climate Envelope Model to identify worldwide areas outside the species' known range that are potentially suitable under current climatic conditions. Projections revealed that this invasive alien species potentially occurs in tropical and some subtropical regions. In the closer vicinity of the snake's known distribution, highest suitability was found for the Northern Mariana Islands, Hawaiian Islands, Madagascar, New Caledonia, and Fiji Islands. If predictions are interpreted as depicting invasiveness potential of B. irregularis, strategies to prevent invasion should focus on these regions. An analysis of potential distributions under different future anthropogenic climate-change scenarios showed that the Fiji Islands, Hawaiian Islands, and Northern Mariana Islands will remain overall most suitable habitat for the Brown Tree Snake. In addition, we noted an increase of suitability in New Zealand.
\end{abstract}

Alien invasive species are a concern in nature conservation because they may have negative impact on native biodiversity and can have major socioeconomic impacts. A remarkable example is the Brown Tree Snake, Boiga irregularis (Merrem, 1802) (Savidge 1987, Rodda and Fritts 1992, Fritts and Rodda 1998, Wiles et al. 2003). This venomous, 1- to 3-m-long arboreal colubrid snake is native to Papua New Guinea, the Solomon Islands, and the northern and eastern coasts of Australia (Figure 1) (Rodda et al. 1999).

\footnotetext{
${ }^{1}$ This work benefited from a grant by the Graduiertenförderung des Landes Nordrhein-Westfalen to D.R. Manuscript accepted 1 February 2009.

${ }^{2}$ Herpetology Department, Zoologisches Forschungsmuseum Alexander Koenig, Adenauerallee 160, 53113 Bonn, Germany.

${ }^{3}$ Biogeography Department, Trier University, 54286 Trier, Germany. de).

${ }^{4}$ Corresponding author: (e-mail: roedder@uni-trier
}

Pacific Science (2010), vol. 64, no. 1:11-22

doi: 10.2984/64.1.011

(C) 2010 by University of Hawai'i Press

All rights reserved
Its status in Sulawesi (Indonesia) is uncertain. Rodda et al. (1999) listed populations from Sulawesi as "native," but Iskandar and Tjan (1996) suggested that B. irregularis may have reached the island only via trade. Ecologically, this snake can be regarded a "generalist" concerning habitat requirements and prey selectivity. Boiga irregularis is known from natural forest and grassland as well as agricultural and urban areas and does not show particular food preferences (Rodda et al. 1999).

The Brown Tree Snake was brought accidentally to several islands in the Pacific shortly after World War II where it successfully established local populations due to obviously unoccupied niches and plentiful naive prey (Rodda et al. 1992). As a result, B. irregularis today is listed among the 100 worst alien invasive species worldwide (Lowe et al. 2000). The most devastating consequences of its introduction are known from Guam, where it led to decimation of vertebrate species including flying foxes, several small terrestrial mammals, and lizards as well as the extinction of eight of the 11 endemic bird species in the 1980s (Savidge 1987, Wiles et al. 2003). It is suggested that $B$. irregularis 


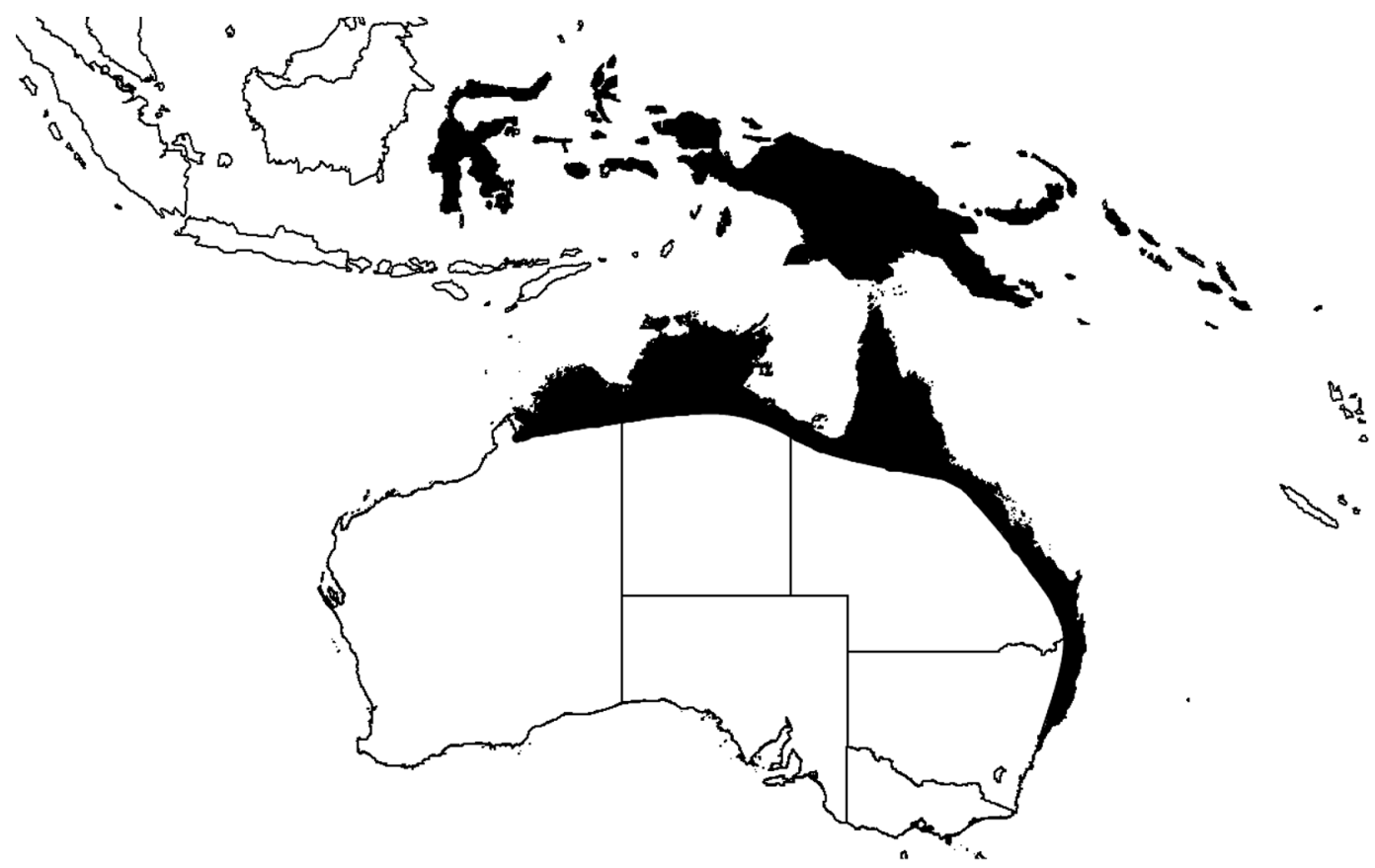

Figure 1. Native distribution of Boiga irregularis. (Adapted from Rodda et al. [1999].)

has substantially altered food web structures, enhancing its effect on native biota and explaining its extraordinarily devastating effect (D'Antonio and Dudley 1995, Fritts and Rodda 1998).

One of the major means of increase of $B$. irregularis distribution is as a stowaway in military equipment and cargo (Fritts 1987, Kraus 2007). Currently, anthropogenic dispersal is most associated with large-scale exercises and personal cargo of people moving from Guam to other duty posts. Also sea freight (container/bulk) may play a role in dispersal (Kraus 2007), and several tree snakes translocated in aircraft cargoes have been detected at Honolulu International Airport in recent years (e.g., Atkinson and Atkinson 2000). During the last decades, the Brown Tree Snake arrived in the Cocos Islands, Diego Garcia, the Hawaiian Islands (Honolulu, O'ahu), Indonesia (Java), Japan, New Zealand, the Northern Mariana Islands (Saipan, Tinian), Malaysia (Singapore), the Marshall Islands (Kwajalein), the Federated States of
Micronesia (Pohnpei), the Ryukyu Islands (Okinawa), Spain (Rota), Taiwan, the United States (Texas, Corpus Christi), and Wake Island (Mito and Uesugi 2004, IUCN Invasive Species Specialist Group 2007). Although it apparently has so far not become residential at any of these places, this list of geographic sites and their distances from the native occurrence demonstrate the snake's "efficiency" in dispersal. A result is that this clearly demands special concern with regard to conservation (Buden et al. 2001, Gill et al. 2001, Kraus and Carvalho 2001, Rodda et al. 2002). In the United States, incursions by $B$. irregularis have been repeatedly intercepted (McCoid et al. 1994), but eradication of established populations is expensive and difficult (Rodda et al. 2002).

It appears to be a question of time until the Brown Tree Snake will establish additional invasive populations. Fritts and Rodda (1998) studied the risk of invasion by the species using biological and natural history information. They concluded that the Mariana, 
Hawaiian, and Caroline islands are most at risk because a native snake fauna is absent and potential prey density is high. Invasion risk will depend on the arrival of founder individuals over time and also on environmental conditions making more areas available for the ectothermic species.

We see an urgent need to identify those regions in which this species finds suitable conditions for successful establishment of invasive populations. Climate Envelope Models are a useful tool to study potential distributions of species under past, current, and future climatic scenarios (e.g., Hijmans and Graham 2006, Malcom et al. 2006, Peterson and Nyári 2007, Carnaval and Moritz 2008, Rödder et al. 2008, Rödder 2009). The scope of the study reported here is to assess the worldwide potential distribution of B. irregularis under current climatic conditions to identify regions with high potential for invasions.

\section{MATERIALS AND METHODS}

\section{Species Records and Climate Data}

A total of 2,679 Boiga irregularis records was available through the Global Biodiversity Information Facility (GBIF, www.gbif.org) and HerpNet databases (www.herpnet.org). In addition, records of invasive populations were obtained from the IUCN Invasive Species Specialist Group (www.issg.org), whereby only records within areas with confirmed reproduction were included. For georeferencing, the Alexandria Digital Library Gazetteer Server Client (www.middleware.alexandria .ucsb.edu/client/gaz/adl/index.jsp) was used.

We used DIVA-GIS 5.4 (Hijmans et al. 2001) to test the accuracy of coordinates (Check Coordinates tool) by comparing information accompanying the species records and locality data extracted from an administrative boundaries database at the smallest possible level (country/state/city). This information should be the same, and any mismatches may reflect errors (see Hijmans et al. 1999). In addition, we used altitudinal information to spot likely errors in the coordinate data when this information was provided with the records used. Altitude was compared with the altitude of the locality in a digital elevation model, using the Extract Values by Points function of DIVA-GIS. Of the total records available, 337 were situated in unique grid cells within the species' native range, classified as being accurate and hence suitable for model building (see later section).

Information on current climate was obtained from the WorldClim database, version 1.4 (www.worldclim.org), which is based on weather conditions recorded between 1950 and 2000 with a grid cell resolution of 2.5 min (Hijmans et al. 2005). It was created by interpolation using a thin-plate smoothing spline of observed climate at weather stations, with latitude, longitude, and elevation as independent variables (Hutchinson 1995, 2004).

\section{Variable Selection}

Rodda et al. (2007) investigated the climate envelope of the Brown Tree Snake in its native geographic range regarding annual mean monthly temperature and precipitation. They found that the amount of precipitation was a good predictor for its distribution. Such a relationship appears to be further supported by natural history observations because the seasonal activity of the Brown Tree Snake is limited to the warmer and wetter summer months in its Australian range (Covacbvich and Limpus 1973, Shine 1991a). It was also observed that the snake is unable to shed properly when the relative humidity is lower than $60 \%$ (Rodda et al. 1999). Within the native distribution of the target species, this dependency is reflected in the geographic range in Australia, where B. irregularis inhabits mainly humid areas close to the sea. Therefore, next to the mean annual values, minimum and maximum annual values may be important, suggesting that "annual precipitation," "precipitation of the wettest month," and "precipitation of the driest month" are suitable predictor variables.

Temperature is a key factor influencing ectothermic species; therefore the "annual mean temperature" is an important variable related to energetic balances and digestive turnover rates. Mathies and Miller (2002) 
showed that temperature seasonality is physiologically important in influencing reproduction. Those authors investigated the effect of two different temperature regimes for eliciting reproduction in male and female $B$. irregularis. They found that specimens maintained at $24^{\circ} \mathrm{C}$ followed by a 60 -day cool period at $19^{\circ} \mathrm{C}$ exhibited substantial reproductive activity. Clutches were produced by females shortly after returning to $24^{\circ} \mathrm{C}$. In contrast, individuals maintained at $28^{\circ} \mathrm{C}$ followed by an identical $19^{\circ} \mathrm{C}$ cooling period exhibited relatively little reproductive activity, and none of the females produced eggs. Considering these effects, we added the "maximum temperature of the warmest month" and "minimum temperature of the coldest month" as predictor variables for model computation.

\section{Climate Envelope Models}

Maxent 3.2.1 (www.cs.princeton.edu/ shapire/maxent) (Phillips et al. 2006) was applied for Climate Envelope Model calculation to assess the potential distribution of the Brown Tree Snake and to map it into geographic space. Maxent is a grid-based machine-learning algorithm following the principles of maximum entropy (Jaynes 1957). The general concept is to find a probability distribution covering the study area that satisfies a set of constraints derived from occurrence data. Each constraint requires that the expected value of an environmental variable or a function thereof must be within a confidence interval of its empirical mean over the presence records. The program chooses the distribution that is closest to uniform and therefore maximizes entropy within all distributions that satisfy the constraints because any other choice would represent constraints on the distribution that are not justified by the data. Maxent is able to incorporate complex dependencies between predictor variables and has been shown to reveal better results than other comparable methods (e.g., Elith et al. 2006, Wisz et al. 2008). The reliability of the results obtained from Maxent models has been confirmed by its capacity to predict novel presence localities for poorly known species (Pearson et al. 2007) and the outcome of introductions of alien invasive species outside the native distribution (e.g., Peterson and Vieglais 2001, Ficetola et al. 2007, Jeschke and Strayer 2008, Rödder et al. 2008, Rödder 2009).

Runs used herein were conducted using the default values for all program settings, whereby randomly chosen background points were restricted to an area defined by a minimum convex polygon including all native records. Herein, the logistic output format with suitability values ranging from 0 (unsuitable) to 1 (optimal) was used, and areas where "clamping" (i.e., nonanalogous climatic condition present in the training area) occurred during projections were subsequently excluded (Philips and Dudík 2008).

Maxent allows for model testing by calculation of the Area Under the Curve (AUC), referring to the ROC (Receiver Operation Characteristic) curve; herein we assessed the ability of the model to distinguish background points from training points (Hanley and McNeil 1982, Phillips et al. 2006). This method is recommended for ecological applications because it is nonparametric (Pearce and Ferrier 2000, but see Lobo et al. 2008). Values of AUC range from 0.5 (random) for models with no predictive ability to 1.0 for models giving perfect predictions. According to the classification of Swets (1988), AUC values $>0.9$ describe "very good," $>0.8$ "good," and >0.7 "useful" discrimination abilities. Maxent allows for an assessment of the relative contribution of variables included using a jackknifing approach.

\section{RESULTS}

\section{Current Potential Distribution}

We obtained "very good" AUC values in the model $(\mathrm{AUC}=0.971)$, and the known invasive range of Boiga irregularis on Guam is situated within higher Maxent classes $(>0.780)$, also confirming the predictive power of the model. The lowest observed Maxent value at the presence point used for model training was 0.201 . Analyses of variable contributions in the model revealed that "annual precipita- 

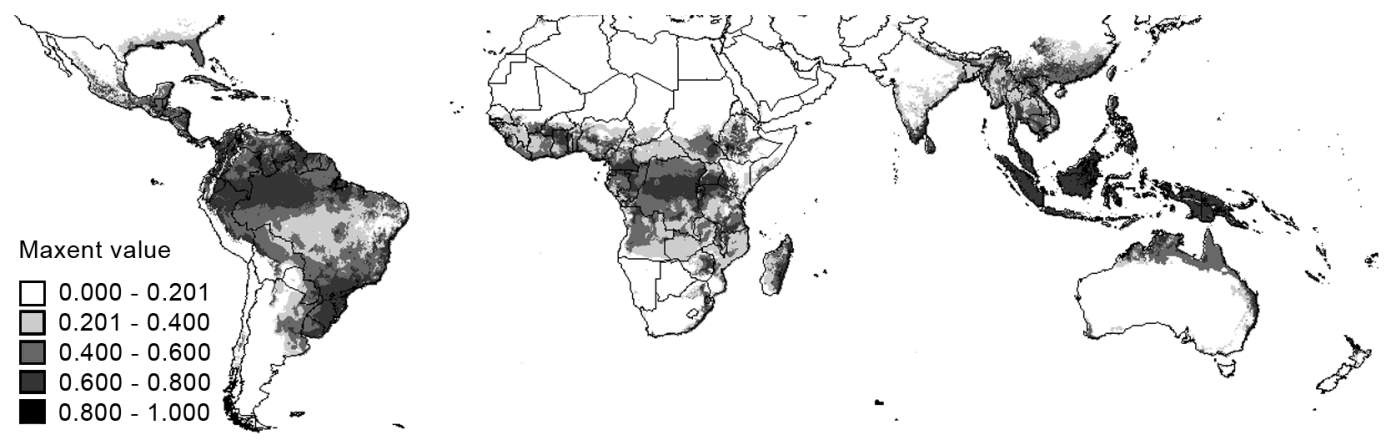

Figure 2. Potential distribution of Boiga irregularis under current climatic conditions. Any area with a Maxent value above 0.201 may be climatically suitable for B. irregularis, although higher Maxent values suggest higher climatic suitability.

tion" with $33.3 \%$ has the highest explanative power, followed by "maximum temperature of the warmest month" (28.5\%), "annual mean temperature" (13.8\%), "precipitation of the driest month" (11.7\%), "precipitation of the wettest month" (7.7\%), and the "minimum temperature of the coldest month" (4.9\%). The relative variable importance obtained via jackknifing from the Maxent model appears to be consistent with natural history observations (see earlier). "Clamping" occurred at very few sites, such as at a very small ridge on the west coast of India. Those areas were excluded from further analyses.

Under current climatic conditions, the Brown Tree Snake has a geographically wide potential distribution throughout almost all the tropics and adjacent subtropical regions, especially widespread within the Southern Hemisphere but also extending to North America including Florida and coastal areas of the Gulf of Mexico (Figure 2). Regarding the general region in which the Brown Tree Snake occurs (i.e., Southeast Asia and Australia), major parts of New Caledonia, New Zealand, the Fiji Islands, and Vanuatu were identified as highly suitable for B. irregularis by the Climate Envelope Model (Figure 3). Guam, the Caroline Islands, and the Northern Mariana Islands including Saipan are all suitable for $B$. irregularis (Figure 3 ). In addition to regions in the vicinity of the species' native geographic range in Southeast Asia, its climate envelope is mirrored in both lowland (e.g., Congo and Amazon basins) and montane (e.g., southern coastal Brazil, Ethiopian highlands) regions. In addition, high suitability was found in the Hawaiian Islands (lower elevations) (Figure 4) and Madagascar (mainly east coast and higher elevations) (Figure 5).

\section{DISCUSSION}

When interpreting results and assessing an invasion risk, it is important to evaluate possible discrepancies between the realized and fundamental climatic niche of $B$. irregularis and the relative contribution of ecological factors other than climate, which may limit the species' current distribution. In addition to a species' climate envelope, these are accessibility limitations and/or biotic interactions such as competition or predation (see also Soberón and Peterson 2005).

\section{Biotic Interactions and/or Accessibility}

Although the modeled potential distribution in the eastern portion of the native range of Boiga irregularis is coincident with the reported distribution (i.e., current species records), that of the western portion is not (Figure 3). Climatically, the Brown Tree Snake can find suitable areas on Borneo, Java, and Sumatra west of Wallace's line, but none of these islands has been successfully invaded, as far as is known (Rodda et al. 1999, IUCN 


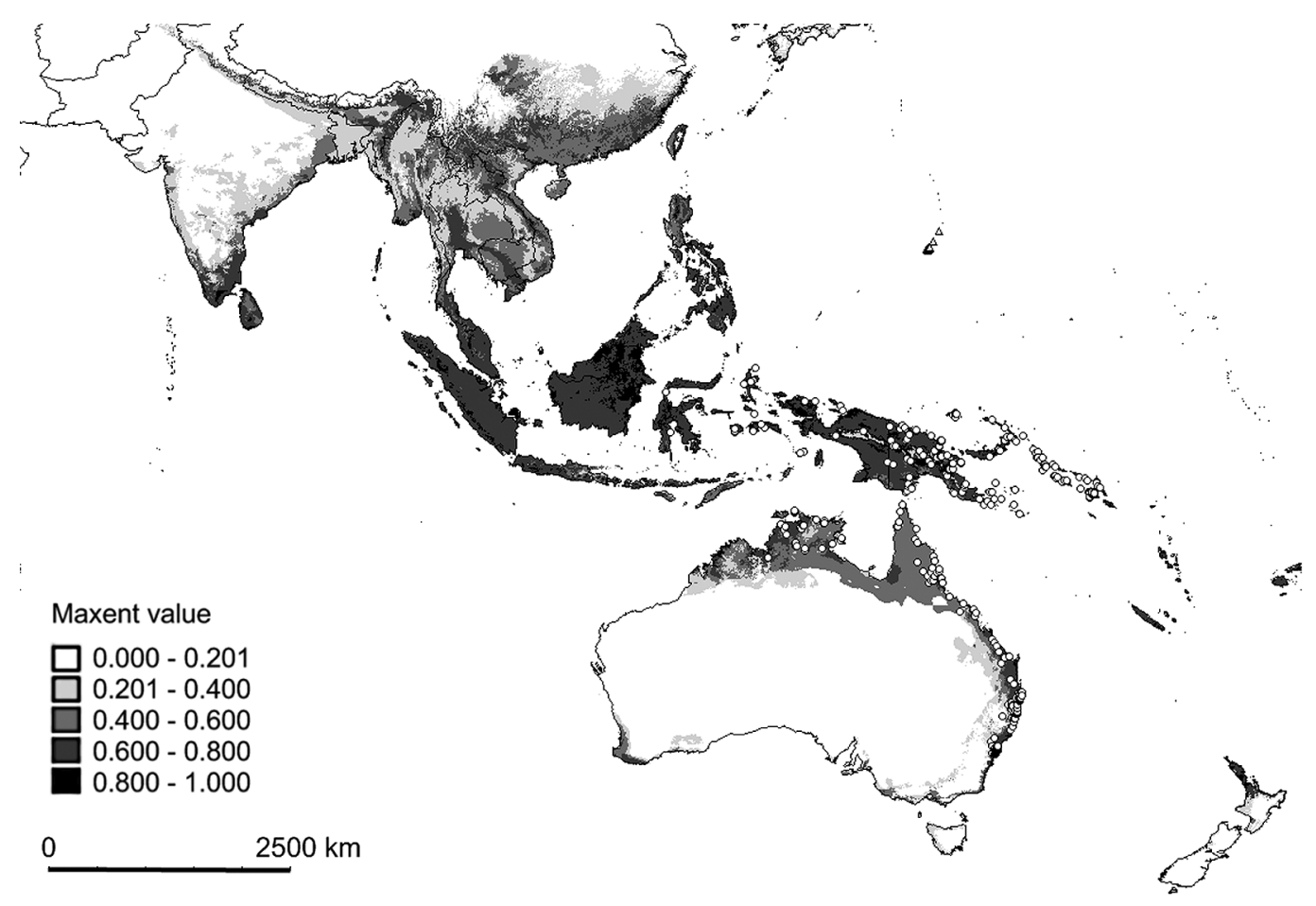

FIgure 3. Potential distribution of Boiga irregularis under current climatic conditions within Southeast Asia and Australia. Higher Maxent values suggest higher climatic suitability. Native-distribution records are indicated as open circles and invasive ones as open triangles.

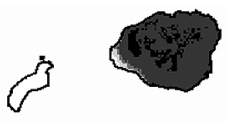

Maxent value

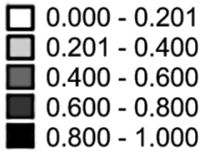

0

$250 \mathrm{~km}$

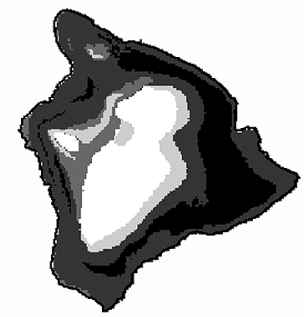

FIgUre 4. Potential distribution of Boiga irregularis under current climatic conditions in the Hawaiian Islands. Higher Maxent values suggest higher climatic suitability. 


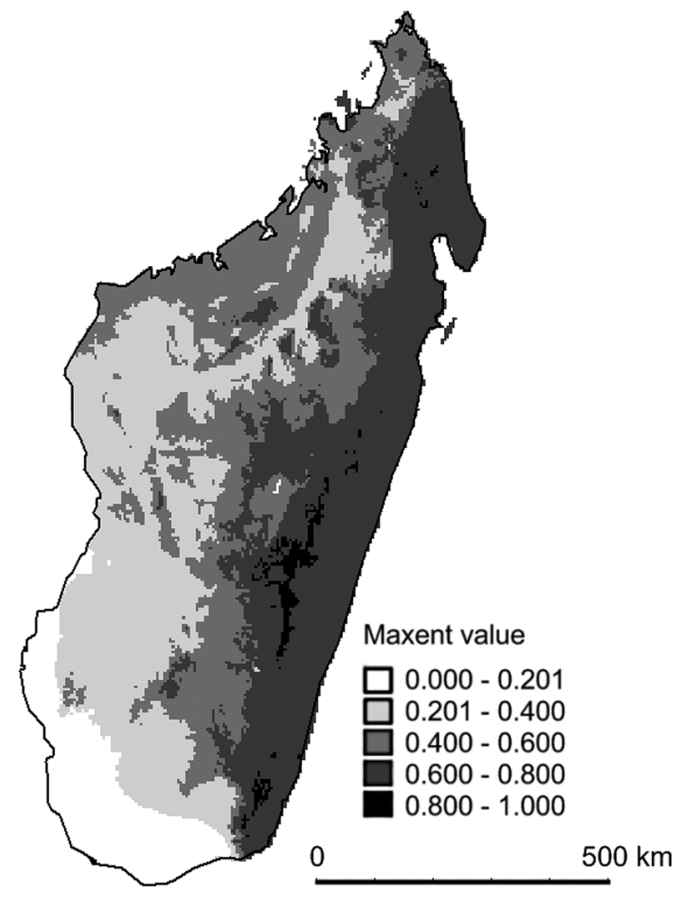

Figure 5. Potential distribution of Boiga irregularis under current climatic conditions in Madagascar. Higher Maxent values suggest higher climatic suitability.

Invasive Species Specialist Group 2007). Possible explanations could be a nonequilibrium of the actual range with climate due to limited accessibility or ongoing spreading, limited prey availability, or the presence of predators or competitors (e.g., Rodda et al. 1999, Araújo and Pearson 2005, Rödder et al. 2008).

Accessibility highly influences the number of jurisdictions where a species can be introduced, which is an important predictor of the probability that a species can establish invasive populations (Bomford et al. 2008). Limited accessibility appears to be an unlikely explanation for the absence of B. irregularis west of Wallace's line. Although faunal exchange between the westernmost populations in Sulawesi and New Guinea and those of adjacent Indonesian islands in past geological times was rather restricted (e.g., Inger and Voris 2001), cargo traffic within Indonesia and adjacent islands increased during the last century and is generally high today (Espada and Kumazawa 2005). Therefore, the chance for accidental introduction of specimens is expected to be high considering that cargo is one of the major means of spreading this species (Kraus 2007).

In the case of the Brown Tree Snake, presence of competitors perhaps best explains the observed pattern. Shine $(1991 a, b)$ suggested that colubrid snakes such as $B$. irregularis are not in noteworthy competition with the endemic elapid snakes and pythons in Australia because they have invaded the continent with ecological specializations that are rare among the endemics. Differences in foraging habitats and in the preferred prey spectrum in comparison with the endemic Australian snakes especially may have enhanced their success (Shine 1991b). This might not be true for the snake fauna west of Wallace's line. The genus Boiga currently comprises 34 species; 11 of them inhabit allopatric ranges adjacent to the native range of $B$. irregularis (B. angulata, B. bengkuluensis, $B$. cynodon, B. dendrophila, B. drapiezii, B. jaspidea, B. multimaculata, B. nigriceps, B. philippina, B. schultzei, B. tanahjampeana) (Uetz et al. 2007), but none of them is known to be invasive (IUCN Invasive Species Specialist Group 2007). It is remarkable that although other snakes occur in sympatry with the Brown Tree Snake, other Boiga species commonly do not. Only at Sulawesi B. dendrophila and $B$. multimaculata occur together with the Brown Tree Snake, but there B. irregularis was only reported from the immediate neighborhood of seaports, where it might have been introduced (Iskandar and Tjan 1996). It is unclear if Sulawesi inland populations actually do exist (Inger and Voris 2001).

It is interesting that the Brown Tree Snake is the only member of the genus known to have established invasive populations. Differences in behavioral traits, which might provide superior abilities to establish invasive populations, are not known. In our opinion, the most likely explanation is that the native range of the Brown Tree Snake is much closer to areas lacking a native terrestrial snake fauna, enhancing the chance of translocation. 


\section{Climate}

Mathies and Miller (2002) showed that a period of cool temperatures elicits reproductive activity in both sexes. Those authors pointed out that temperatures experienced during the artificial hibernation were much lower than the snakes would experience on Guam, where temperature seasonality is relatively invariant throughout the year $\left( \pm 1^{\circ} \mathrm{C}\right.$ [Rodda et al. 1999]). Comparing native populations in Australia and invasive populations on Guam, Moore et al. (2005) found that snake specimens from Guam exhibited substantially reduced body conditions compared with individuals from Australia. Those authors suggested that Brown Tree Snakes on Guam were living under stressful conditions, possibly due to overcrowding and overexploitation of food resources, resulting in decreased adult size/weight and suppressed reproduction. The findings of Mathies and Miller (2002) might provide an additional explanation for their finding because environmental stress may cause absence of hibernation and disturbed seasonal reproductive cycles. However, although reproductive activity on Guam may be suppressed and desynchronized, only minor enhanced fluctuations in temperature throughout the year may be sufficient to elicit reproduction; therefore fluctuations and/or extreme weather events due to anthropogenic climate change might enhance the snake problem. Furthermore, the observation that moderate hibernation enhances the reproductive cycle allows the hypothesis that Boiga irregularis may also find climatically suitable habitats in more temperate regions with a higher degree of seasonality, such as the northern parts of New Zealand, Japan, or Taiwan. Generally, climatic similarities of a novel environment compared with that of the native range enhance the probability of successful establishment of alien invasive species (Bomford et al. 2008).

\section{Which Regions Are at High Risk of Invasion by the Brown Tree Snake?}

Fritts and Rodda (1998) studied the risk of invasion by the Brown Tree Snake using bio- logical and natural history information. They concluded that the Northern Mariana, Hawaiian, and Caroline islands are most at risk because a native (competing) snake fauna is absent and prey is available. Because the Mariana and Caroline islands are comparable in terms of faunal composition with Guam, an invasion in those islands may have similarly dramatic ecological consequences. The faunal composition of the Hawaiian Islands might also generally support the establishment of Boiga irregularis (Kraus and Carvalho 2001). However, predictions based on natural history and biological information appear to bear a higher degree of uncertainty there because the faunal composition of the Hawaiian Islands is distinctly different from that found on Guam (Fritts and Rodda 1998).

Climate Envelope Model predictions obtained in this paper confirm the expected climatic suitability of the Northern Mariana, Hawaiian, and Caroline islands. In addition, our models highlight major parts of central Africa, Central America, South America, a broad swath of the southeastern United States coastal plain (coincident with the prediction presented by Rodda et al. [2007]), New Caledonia, New Zealand, and Madagascar as having high climatic suitability for $B$. irregularis. Records of Brown Tree Snakes that were accidentally imported to Hawai'i and New Zealand already exist (Gill et al. 2001, IUCN Invasive Species Specialist Group 2007), and it may be feared that the Brown Tree Snake will establish there. Impacts may be enhanced due to high availability of prey affecting population dynamics of the invader. Establishment of B. irregularis in New Zealand, in addition, may be facilitated due to the absence of competitors, because only sea snakes occur there (Hydrophiidae). Similarly, for New Caledonia and the Fiji Islands only 19 and seven snake species are known, respectively (Uetz et al. 2007). Sixteen of the New Caledonian species also are hydrophiids, two are fossorial Thyphlopida, but Candoia bibroni (Boidae) could be a potential competitor to the Brown Tree Snake. At Fiji, there are three species each of hydrophiids and thyphlopids plus Candoia bibroni.

It must be noted that possible discrepan- 
cies between the realized climatic niche (climatic conditions within realized distribution) and the fundamental climatic niche of $B$. irregularis may lead to an underestimation of threat in some regions. Unfortunately, the relationship between realized and fundamental niches can be addressed only experimentally but not with climate envelope model approaches, leaving some degree of uncertainty. However, it is interesting that the potential distribution of $B$. irregularis derived from our model is remarkably coincident with the realized distributions of all other members of the genus Boiga, implying that climatic niches are rather conservative within the genus (at least regarding the variables chosen herein) and that we captured a great part of its fundamental niche with our model. However, areas outside the proposed potential distribution may exhibit climatic conditions different from those present within the realized distribution of $B$. irregularis, but they may not necessarily be unsuitable.

\section{CONCLUSIONS}

We conclude that Boiga irregularis is a species causing a high extinction risk to endemic faunas in regions where specimens are frequently translocated via military shipment and cargo (Fritts 1987, Kraus 2007, Bomford et al. 2008) and that are suitable under current climatic conditions and lack competitors, namely the Northern Mariana and Hawaiian islands, New Caledonia, and the Fiji Islands. Climatically suitable regions harboring minimal or lacking native snake species are likely to be most impacted. There, availability of resources may be enhanced compared with an ecosystem already harboring competing snakes.

Under future anthropogenic climate change, the situation will not change essentially, but climatic suitability for B. irregularis will generally remain high in Madagascar and New Caledonia and even increase in New Zealand (D.R., unpubl. data). Possible routes for spreading of the species to Madagascar, New Caledonia, and the Fiji Islands include sea cargo, military equipment (Fritts 1987, Kraus 2007), and also accidental transloca- tions via aircraft cargoes (Atkinson and Atkinson 2000). Preventing further spreading to the areas highlighted may depend on maintaining strict cargo checks of boats and searches at airports.

\section{ACKNOWLEDGMENTS}

We are grateful to Marcelo R. Duarte, Tom C. Mathies, and Mirco Solé, who helped with literature used herein. Three anonymous reviewers helped improve this paper.

\section{Literature Cited}

Araújo, M. B., and R. G. Pearson. 2005. Equilibrium of species' distribution with climate. Ecography 28:693-695.

Atkinson, I. A. E., and T. J. Atkinson. 2000. Land vertebrates as invasive species on the islands of the South Pacific Regional Environment Programme. Pages 19-84 in G. Sherely, ed. Invasive species in the Pacific: A technical review and draft regional strategy. South Pacific Regional Environment Program, Samoa.

Bomford, M., F. Kraus, S. C. Barry, and E. Lawrence. 2008. Predicting establishment success for alien reptiles and amphibians: The role of climate matching. Biol. Invasions 11:713-724.

Buden, D. W., D. B. Lynch, and G. R. Zug. 2001. Recent records of exotic reptiles on Pohnpei, eastern Caroline Islands, Micronesia. Pac. Sci. 55:65-70.

Carnaval, A. C., and C. Moritz. 2008. Historical climate modelling predicts patterns of current biodiversity in the Brazilian Atlantic forest. J. Biogeogr. 25:1187-1201.

Covacbvich, J., and C. Limpus. 1973. Two large winter aggregations of three species of tree-climbing snakes in south-eastern Queensland. Herpetofauna 6:16-21.

D'Antonio, C. M., and T. L. Dudley. 1995. Biological invasions as agents of change on islands versus mainlands. Pages 103121 in P. M. Vitousek, L. L. Loope, and H. Andersen, eds. Islands: Biological diversity and ecosystem function. Ecological Studies. Springer, Berlin. 
Elith, J., C. H. Graham, R. P. Anderson, M. Dudik, S. Ferrier, A. Guisan, R. J. Hijmans, F. Huettmann, J. R. Leathwick, A. Lehmann, J. Li, L. G. Lohmann, B. A. Loiselle, G. Manion, C. Moritz, M. Nakamura, Y. Nakazawa, J. M. M. Overton, A. T. Perterson, S. J. Phillips, K. Richardson, R. Scachetti-Pereira, R. E. Shapire, J. Soberón, S. Williams, M. S. Wisz, and N. E. Zimmermann. 2006. Novel methods improve prediction of species' distributions from occurrence data. Ecography 29:129-151.

Espada, I. C., and K. Kumazawa. 2005. O-D structure of domestic maritime traffic in Indonesia. Proc. East. Asia Soc. Transport. Stud. 5:647-660.

Ficetola, G. F., W. Thuiller, and C. Miaud. 2007. Prediction and validation of the potential global distribution of a problematic alien species: The American Bullfrog. Divers. Distrib. 13:476-485.

Fritts, T. H. 1987. Movements of snakes via cargo in the Pacific region. Elepaio 47:17-18.

Fritts, T. H., and G. H. Rodda. 1998. The role of introduced species in the degradation of island ecosystems. Annu. Rev. Ecol. Syst. 29:113-140.

Gill, B. J., D. Bejakovich, and A. H. Whitaker. 2001. Records of foreign reptiles and amphibians accidentally imported to New Zealand. N. Z. J. Zool. 28:351-359.

Hanley, J., and B. McNeil. 1982. The meaning of the use of the area under a receiver operating characteristic (ROC) curve. Radiology 143:29-36.

Hijmans, R. J., S. E. Cameron, J. L. Parra, P. G. Jones, and A. Jarvis. 2005. Very high resolution interpolated climate surfaces for global land areas. Int. J. Climatol. 25:1965-1978.

Hijmans, R. J., J. M. Cruz, R. Rojas, and L. Guarino. 2001. DIVA-GIS, version 1.4. A geographic information system for the management and analysis of genetic resources data. Manual. International Potato Center and International Plant Genetic Resources Institute, Lima, Peru.

Hijmans, R. J., and C. H. Graham. 2006. The ability of climate envelope models to predict the effect of climate change on species distributions. Global Change Biol. 12:2272-2281.

Hijmans, R. J., M. Schreuder, J. De la Cruz, and L. Guarino. 1999. Using GIS to check coordinates of genebank accessions. Genet. Resour. Crop Evol. 46:291-296.

Hutchinson, M. F. 1995. Interpolating mean rainfall using thin plate smoothing splines. Int. J. Geogr. Inf. Sys. 9:385-403.

- 2004. Anusplin, version 4.3. Centre for Resource and Environment Studies, The Australian National University, Canberra.

Inger, R. F., and H. K. Voris. 2001. The biogeographical relations of the frogs and snakes of Sundaland. J. Biogeogr. 28:863891.

Iskandar, D. T., and K.-N. Tjan. 1996. The amphibians and reptiles of Sulawesi, with notes on the distribution and chromosome number of frogs. Pages 39-46 in D. J. Kitchener and A. Suyanto, eds. Proceedings of the 1st International Conference on Eastern Indonesian-Australian Vertebrate Fauna, Mandao. Western Australian Museum for lembaga Ilmu Penetahuan Indonesia, Perth, Australia.

IUCN Invasive Species Specialist Group. 2007. www.issg.org.

Jaynes, E. T. 1957. Information theory and statistical mechanics. Phys. Rev. 106:620630.

Jeschke, J. M., and D. L. Strayer. 2008. Usefulness of bioclimatic models for studying climate change and invasive species. Ann. N. Y. Acad. Sci. 1134:1-24.

Kraus, F. 2007. Using pathway analysis to inform prevention strategies for alien reptiles and amphibians. Pages 94-103 in G. W. Witmer, W. C. Pitt, and K. A. Fagerstone, eds. Managing vertebrate invasive species: Proceedings of an international symposium. USDA/APHIS/WS, National Wildlife Research Center, Fort Collins, Colorado.

Kraus, F., and D. Carvalho. 2001. The risk to Hawai'i from snakes. Pac. Sci. 55:409-417.

Lobo, J. M., A. Jiménez-Valverde, and R. Real. 2008. AUC: A misleading measure of the performance of predictive distribution models. Global Ecol. Biogeogr. 17:145-151. 
Lowe, S., M. Browne, S. Boudjelas, and M. De Poorter. 2000. 100 of the world's worst invasive alien species: A selection from the Global Invasive Species Database. The Invasive Species Specialist Group (ISSG), Auckland.

Malcom, J. R., D. Liu, R. P. Neilson, L. Hansen, and L. Hannah. 2006. Global warming and extinction of endemic species from biodiversity hotspots. Conserv. Biol. 20:538-548.

Mathies, T., and L. A. Miller. 2002. Cool temperatures elicit reproduction in a biologically invasive predator, the Brown treesnake. Zoo Biol. 22:227-238.

McCoid, M. J., T. H. Fritts, and E. W. Campbell. 1994. A Brown tree snake (Colubridae: Boiga irregularis) sighting in Texas. Tex. J. Sci. 46:365-368.

Mito, T., and T. Uesugi. 2004. Invasive alien species in Japan: The status quo and new regulation for prevention of their adverse effects. Global Environ. Res. 8:171-191.

Moore, I. T., M. J. Greene, A. T. Lerner, C. E. Asher, R. W. Krohmer, D. L. Hess, J. Whittier, and R. T. Mason. 2005. Physiological evidence for reproductive suppression in the introduced population of brown tree snakes (Boiga irregularis) on Guam. Biol. Conserv. 121:91-98.

Pearce, J., and S. Ferrier. 2000. An evaluation of alternative algorithms for fitting species distribution models using logistic regression. Ecol. Modell. 128:128-147.

Pearson, R. G., C. J. Raxworthy, M. Nakamura, and A. T. Peterson. 2007. Predicting species distributions from small numbers of occurrence records: A test case using cryptic geckos in Madagascar. J. Biogeogr. 34:102-117.

Peterson, A. T., and À. S. Nyári. 2007. Ecological niche conservatism and Pleistocene refugia in the Thrush-like Mourner, Shifforinis sp., in the Neotropics. Evolution 62:173-183.

Peterson, A. T., and D. A. Vieglais. 2001. Predicting species invasions using ecological niche modeling: New approaches from bioinformatics attack a pressing problem. BioScience 51:363-371.

Phillips, S. J., R. P. Anderson, and R. E. Schapire. 2006. Maximum entropy model- ling of species geographic distributions. Ecol. Modell. 190:231-259.

Phillips, S. J., and M. Dudík. 2008. Modeling of species distributions with Maxent: New extensions and comprehensive evaluation. Ecography 31:161-175.

Rodda, G. H., and T. H. Fritts. 1992. The impact of the introduction of the colubrid snake Boiga irregularis on Guam's lizards. J. Herpetol. 26:166-174.

Rodda, G. H., T. H. Fritts, E. W. Campbell, K. Dean-Bradley, G. Perry, and C. P. Qualls. 2002. Practical concerns in the eradication of island snakes. Pages 260265 in C. R. Veitch and M. N. Clout, eds. Turning the tide: The eradication of invasive species. Proceedings of the International Conference on Eradication of Island Invasives. Occasional Paper of the IUCN Species Survival Commission, Gland, Switzerland, and Cambridge, United Kingdom.

Rodda, G. H., T. H. Fritts, and P. J. Conry. 1992. Origin and population growth of the Brown tree snake, Boiga irregularis, on Guam. Pac. Sci. 46:46-57.

Rodda, G. H., T. H. Fritts, M. J. McCoid, and E. W. Campbell. 1999. An overview of the biology of the Brown tree snake, Boiga irregularis, a costly introduced pest on Pacific islands. Pages 44-80 in G. H. Rodda, Y. Sawai, D. Chiszar, and H. Tanaka, eds. Problem snake management: The Habu and the Brown Tree Snake. Cornell University Press, Ithaca, New York.

Rodda, G. H., R. N. Reed, and C. S. Jarnevich. 2007. Climate matching as a tool for predicting potential North American spread of Brown treesnakes. Pages 138145 in G. W. Witmer, W. C. Pitt, and K. A. Fangerstone, eds. Managing vertebrate invasive species: Proceedings of an international symposium. USDA/APHIS/ WS, National Wildlife Research Center, Fort Collins, Colorado.

Rödder, D. 2009. 'Sleepless in Hawaii': Does anthropogenic climate change enhance ecological and socioeconomic impacts of the alien invasive Eleutherodactylus coqui Thomas, 1966 (Anura: Eleutherodactylidae)? North-West. J. Zool. 5:16-25. 
Rödder, D., M. Solé, and W. Böhme. 2008. Predicting the potential distribution of two alien invasive housegeckos (Gekkonidae: Hemidactylus frenatus, Hemidactylus mabouia). North-West. J. Zool. 4:236-246.

Savidge, J. A. 1987. Extinction of an island forest avifauna by an introduced snake. Ecology 68:660-668.

Shine, R. 1991a. Australian snakes: A natural history. Cornell University Press, Ithaca, New York.

- 1991b. Strangers in a strange land: Ecology of the Australian colubrid snakes. Copeia 1991:120-131.

Soberón, J., and A. T. Peterson. 2005. Interpretation of models of fundamental ecological niches and species' distributional areas. Biodiv. Inf. 2:1-10.
Swets, K. 1988. Measuring the accuracy of diagnostic systems. Science (Washington, D.C.) 240:1285-1293.

Uetz, P., J. Goll, and J. Hallermann. 2007. Die TIGR-Reptiliendatenbank. Elaphe 15:22-25.

Wiles, G. J., J. Bart, R. E. Beck, and C. F. Aguon. 2003. Impacts of the Brown tree snake: Patterns of decline and species persistence in Guam's avifauna. Conserv. Biol. 17:1350-1360.

Wisz, M. S., R. J. Hijmans, A. T. Peterson, C. H. Graham, A. Guisan, and NPSDW Group. 2008. Effects of sample size on the performance of species distribution models. Divers. Distrib. 14:763-773. 